\title{
Strangulation and necrosis of right hemicolon as an extremely rare complication of Spigelian hernia
}

\author{
Georgios Velimezis ${ }^{1}$, Nikolaos Vassos ${ }^{2}$, Georgios Kapogiannatos ${ }^{1}$, Dimitrios Koronakis ${ }^{1}$, \\ Christos Salpiggidis ${ }^{1}$, Evangelos Perrakis ${ }^{1,3}$, Aristotelis Perrakis ${ }^{2}$
}

\begin{abstract}
${ }^{1}$ Department of Surgery, Western Attica General Hospital, Athens, Greece ${ }^{2}$ Department of Surgery, University of Erlangen-Nuremberg, Erlangen, Germany ${ }^{3}$ Department of Surgery, General Hospital Nikea, Piraeus, Greece
\end{abstract}

Submitted: 15 September 2014

Accepted: 10 November 2014

Arch Med Sci 2016; 12, 2: 469-472

DOI: $10.5114 /$ aoms.2016.59273

Copyright @ 2016 Termedia \& Banach

Andrian van der Spigel was the first to describe the semilunar line, in 1645 [1]. The Spigelian aponeurosis is formed by the fusion of the aponeurosis of the internal oblique muscle and the aponeurosis of the transversus abdominis muscle. The linea semilunaris forms the lateral margin and the lateral edge of the rectus muscle the medial margin of the Spigelian aponeurosis. It extends from the costal cartilage of the $8^{\text {th }}$ rib to the symphysis pubis [1-3]. In the upper abdominal wall, the Spigelian aponeurosis is posterior to the rectus muscle, making it difficult even for the experienced surgeon to locate a fascial defect during the physical examination. Superior to the umbilical region, the aponeurosis of the internal oblique crosses over the transverses, creating a strong abdominal wall barrier. Beneath the umbilical region the aponeurosis forms a weak barrier that is susceptible to protruding peritoneal sacs or extraperitoneal fat [1, 3-5]. Spigelian hernia was first reported by Klinklosch in 1764. More than half of all Spigelian hernias are located in a $6 \mathrm{~cm}$ wide region beneath the umbilicus and superior to the inferior epigastric vessels. This region is referred as "the Spigelian hernia belt" $[1,2]$. The most common symptom of Spigelian hernia is pain (60\%) due to contraction of the abdominal musculature. Another common symptom is a palpable abdominal mass in 35\% of cases [6-17]. Predisposing factors were collagen disorders, age, obesity, rapid weight loss, multiple pregnancies, chronic pulmonary disease, trauma, iatrogenic causes and congenital disorders [3, 10, 18]. Once Spigelian hernia is diagnosed, there is a need for surgical treatment because of the high risk for serious complications. Emergency surgery is estimated to be performed in $21-33 \%$ of cases, due to incarceration and strangulation [2, 9-11, 15-22].

Here, we present a unique case of Spigelian hernia with incarceration and obstruction of the terminal ileum, appendix, cecum and right hemicolon that was treated with a major surgical procedure on an emergency basis.

A 70-year-old white female patient (body mass index: $34.2 \mathrm{~kg} / \mathrm{m}^{2}$ ) referred to the Surgical Department of the Western Attica Hospital with abdominal pain in the right lower quadrant (RLQ), mild abdominal distention and progressive constipation. Her past medical history was significant for constipation symptoms, nausea and recurrent fever. Her past surgical history was not remarkable, and there was not a triggering effect for bowel entrapment. The physical examination revealed a $18 \times 10 \times 12 \mathrm{~cm}$

\author{
Corresponding author: \\ Aristotelis Perrakis MD \\ Department \\ of Surgery University \\ of Erlangen-Nuremberg \\ Krankenhausstr. 12 \\ 91054 Erlangen, Germany \\ Phone: +4991318533100 \\ Fax: +4991318536294 \\ E-mail: aristotelis.perrakis@ \\ uk-erlangen.de
}


palpable mass in the RLQ. The overlying skin was irritated with signs of an extended inflammatory reaction (Figure 1). Laboratory examinations revealed leukocytosis (16 700 white blood cells/ $\mu$ l) and a major electrolyte disorder (hypokalemia (3.0 mmol/l) and hyponatremia (129 mmol/l)). The plain abdominal $\mathrm{X}$-ray examination revealed gas-fluid levels indicating large bowel obstruction (Figure 2). Due to these findings an immediate surgical intervention under general anesthesia was performed. The surgical exploration was carried out via a right pararectal anterior approach over the mass. Laparotomy confirmed a great mass pro-

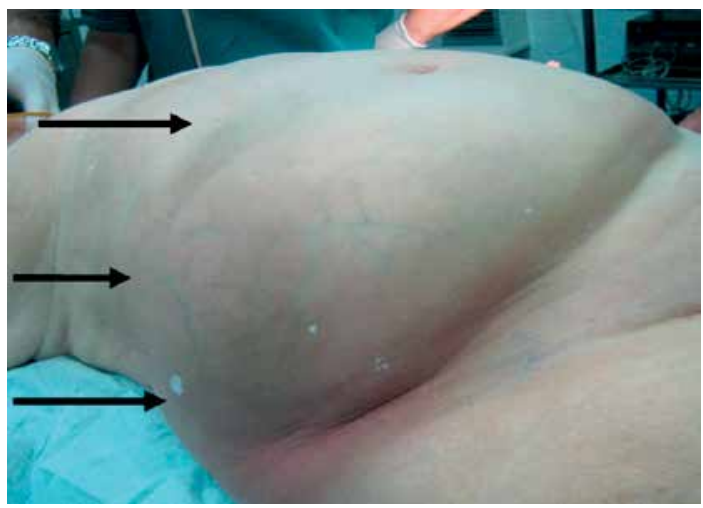

Figure 1. Huge palpable mass in the right lower quadrant of the abdomen
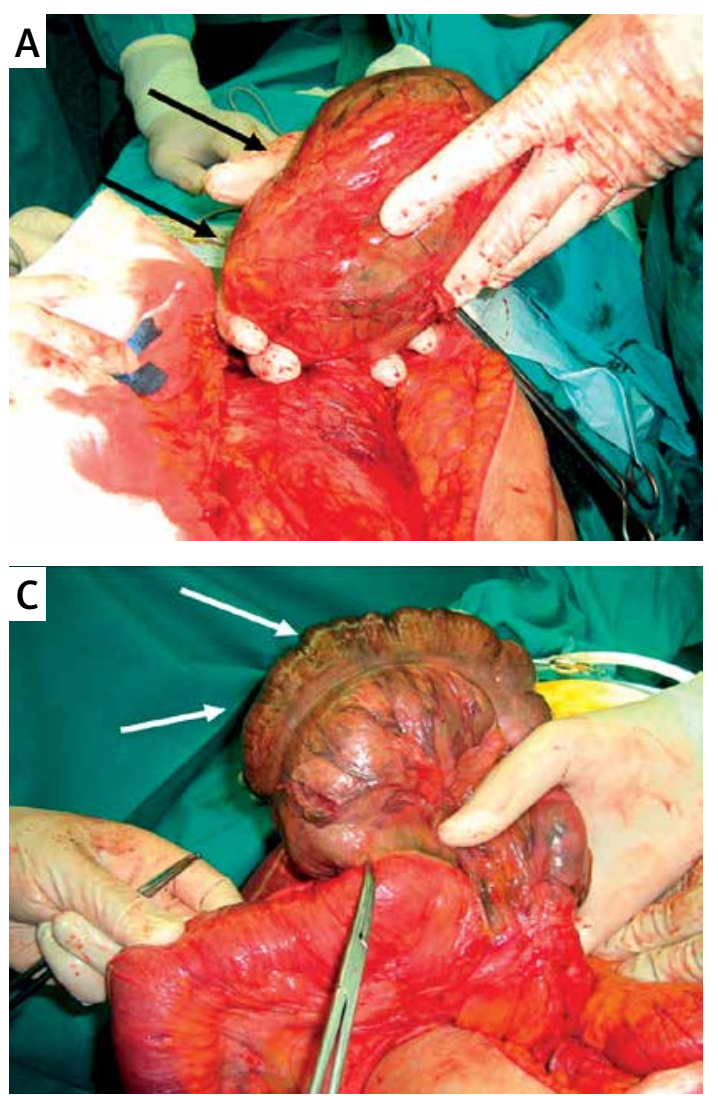

Figure 3. A - Inflammatory mass in subcutaneous tissue. B - Neck of Spigelian hernia. C - Necrosis of intestinal wall. D - Surgical specimen after right hemicolectomy

truding through the neck of a Spigelian hernia of $15 \times 8 \times 10 \mathrm{~cm}$ size (Figure $3 \mathrm{~A}$ ). After opening the hernia sac, strangulation of the cecum, terminal ileum and ascending colon with extended necrosis of the intestinal wall was found (Figure $3 \mathrm{~B}, \mathrm{C}$ ). A right hemicolectomy was performed (Figure $3 \mathrm{D}$ ), and the defect in the abdominal wall was repaired by Prolene Hernia System $(20 \times 15 \mathrm{~cm})$ according to our technique [23]. The histopathological examination showed an extended necrosis, without any signs of malignancy. The patient was discharged on the $9^{\text {th }}$ postoperative day after an unremarkable hospital course. The patient underwent a colonos-

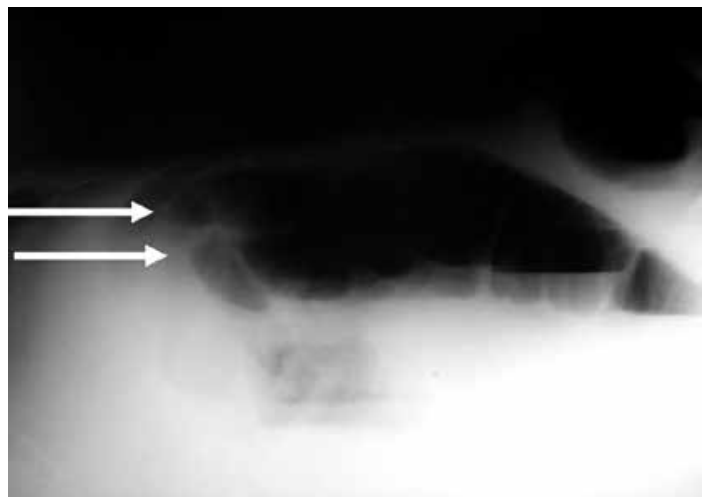

Figure 2. Plain abdominal X-ray examination with gas-fluid levels indicating large bowel obstruction
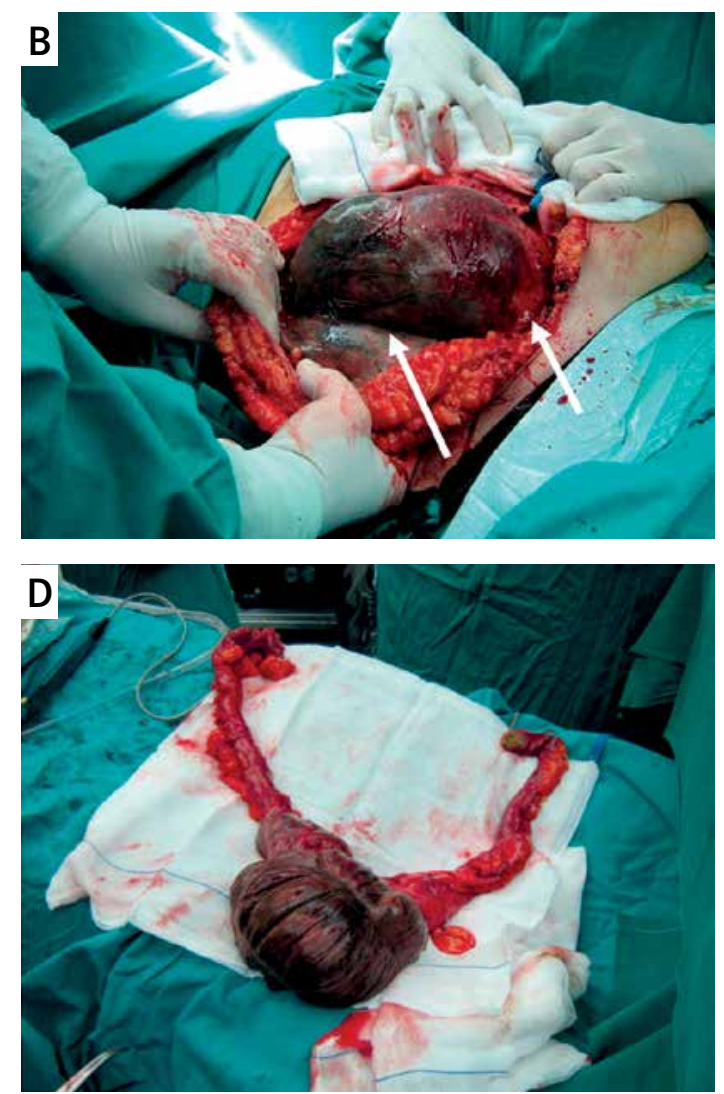
copy 12 weeks after surgical treatment in order to exclude a malignancy of the colon, and after 5 years of follow-up the patient is doing well without any evidence of hernia recurrence.

The most common symptoms of Spigelian hernia are pain (60\%) and a palpable abdominal mass in $35 \%$ of cases [6]. Whether a Spigelian hernia should be diagnosed through physical examination remains a controversial matter: In more than $50 \%$ of cases the physical examination alone is not enough to establish the diagnosis [7]. However, according to Larson, patients' history and physical examination alone establish the diagnosis of Spigelian hernia in $74 \%$ of cases [8]. Many authors have reported that many Spigelian hernias may remain unclear until laparotomy is performed. Weiss et al. reported in a series of 178 patients that the preoperative diagnosis was correct in 92 (51.7\%) cases [9]. The diameter of the neck is usually about $0.5-2 \mathrm{~cm}$, and due to this fact the risk of obstruction and incarceration is high $(21 \%)[10,11]$. The hernia sac usually contains preperitoneal fat or greater omentum, but there are cases in which the sac contains parts of the small bowel or other solid organs [2]. Colonic obstruction is, nevertheless, a very rare condition. To our knowledge, only 10 cases have been reported in the literature (Table I) [12-17]. Abdominal X-ray examination may show signs of ileus in case of incarceration but is not specific enough to reveal the cause of the obstruction. Ultrasonography and computed tomography can clearly define the defect of the abdominal wall as well as the contents of the hernia sac $[19,20]$. Once Spigelian hernia is diagnosed, there is a need for surgical treatment because of the high risk of further serious complications. Emergency surgery is estimated to be performed in $21-33 \%$ of cases, due to incarceration and strangulation [2, 9-11, 15]. The surgical procedures performed for repair of Spigelian hernia are generally classified as follows: open (primary suture repair, mesh-repair preperitoneal or intraperitoneal) and laparoscopic (intra- or preperitoneal). Open procedures are still widely used, because of the preoperative uncertainty of diagnosis and the high rate of emergency surgery, but the laparoscopic approach is gaining increased importance mainly in uncomplicated cases [11, 19, 21, 22].

\section{Acknowledgments}

Georgios Velimezis and Nikolaos Vassos contributed equally to this manuscript.

\section{Conflict of interest}

The authors declare no conflict of interest.

\section{References}

1. Skandalakis PN, Zoras O, Skandalakis JE, Mirilas P. Spigelian hernia: surgical anatomy, embryology, and technique of repair. Am Surg 2006; 72: 42-8.

2. Spangen L. Spigelian hernia. World J Surg 1989; 13: 573-80.

3. Sanchez-Montes I, Deysine M. Spigelian hernias. Arch Surg 1988; 133: 670-2.

4. Read RC. Observation on the etiology of spigelian hernia. Ann Surg 1960; 152: 1004-9.

5. Olson RO, Davis WC. Spigelian hernia: rare or obscure? Am J Surg 1968; 116: 842-6.

6. Jain KM, Hastings OM, Kurz VP. Spigelian hernia. Am Surg 1977; 43: 596-600.

Table I. Reported cases with colonic obstruction secondary to a Spigelian hernia

\begin{tabular}{|c|c|c|c|c|c|}
\hline$N$ & Author (year) & Age/gender & Site of hernia & Involved segment & Type of surgery \\
\hline 1 & Spierl (1980) & $58 / M$ & RLQ & Cecum and ascending colon & Right hemicolectomy \\
\hline 2 & Le Joliff (1985) & $72 / F$ & LLQ & Descending colon & Hartmann operation \\
\hline 3 & Le Joliff (1985) & $63 / F$ & LLQ & Sigmoid & No resection \\
\hline 4 & Le Joliff (1985) & $81 / F$ & LLQ & Descending colon & $\begin{array}{l}\text { Suture of the } \\
\text { perforated site }\end{array}$ \\
\hline 5 & Brahmbhatt (1990) & $70 / F$ & LLQ & Sigmoid & No resection \\
\hline 6 & Benito (1999) & $67 / F$ & LLQ & Sigmoid & No resection \\
\hline 7 & Losanoff (2001) & $65 / F$ & LLQ & Sigmoid & No resection \\
\hline 8 & Fisichella (2007) & $78 / F$ & RLQ & Cecum & Not stated \\
\hline 9 & Miller (2008) & $57 / M$ & LLQ & Sigmoid & No resection \\
\hline 10 & Salemis (2010) & $41 / M$ & RLQ & $\begin{array}{l}\text { Ascending colon, small bowel } \\
\text { loop, portion of greater } \\
\text { omentum }\end{array}$ & No resection \\
\hline 11 & Our case & $70 / F$ & RLQ & $\begin{array}{l}\text { Terminal ileum, cecum and } \\
\text { ascending colon }\end{array}$ & Right hemicolectomy \\
\hline
\end{tabular}


7. Stirnemann $\mathrm{H}$. The spigelian hernia: Missed? Rare? Puzzling diagnosis? Chirurg 1982; 53: 314-7.

8. Larson DW, Farley DR. Spigelian henrias: repair and outcome for 81 patients. World J Surg 2002; 26: 1277-81.

9. Weiss Y, Lernau OZ, Nisen S. Spigelian hernia. Ann Surg 1974; 180: 567-72.

10. Montes IS, Deysine M. Spigelian and other uncommon hernia repair. Surg Clin North Am 2003; 83: 1235-53.

11. Moreno-Egea A, Flores B, Girela E, Martin JG, Aguayo JL, Canteras M. Spigelian hernia: bibliographical study and presentation of a series of 28 patients. Hernia 2002; 6: 167-70.

12. Losanoff JE, Jones JW, Richman BW. Recurrent spigelian hernia: a rare cause of colonic obstruction. Hernia 2001; 5: 101-4.

13. Fisichella PM, Harwell J, Brosnan J, Abcarian H. Richters hernia through a spigelian defect of the abdominal wall. Am J Surg 2007; 193: 69-70.

14. Miller R, Lifschitz O, Mavor E. Incarcerated spigelian hernia mimicking colon carcinoma. Hernia 2008; 12: 87-9.

15. Artioukh DY, Walker SJ. Spigelian hernia: presentation, diagnosis and treatment. J R Coll Surg Edinb 1996; 441: 241-3.

16. Bryk D. Spigelian hernia containing sigmoid colon. Am J Roentgenol Radium Ther Nucl Med 1967; 99: 71-3.

17. Salemis NS, Kontoravdis N, Gourgiotis S, Panagiotopoulos N, Gakis C, Dimitrakopoulos G. Colonic obstruction secondary to incarcerated Spigelian hernia in a severely obese patient. Int I Surg Case Rep 2010; 1: 27-9.

18. Spangen L. Spigelian hernia. In: Prostheses and abdominal wall hernias. Bendavid R (ed.) Austin RG Landes 1994; 563.

19. Bennett $D$. Incidence and management of primary abdominal wall hernias: umbilical, epigastic and spigelian. In: Nyhous and condon's hernia. $5^{\text {th }}$ ed. Fitzgibbons RJ, Greenbourg AG (eds). Lippincot Williams and Wilkins, Philadelphia 2002; 339.

20. Balthazar EJ, Subramanyam BR. Radiographic diagnosis of spigelian hernia. Am J Gastroenterol 1983; 78: 525-8.

21. Palavinelu C, Vijaykumar M, Jani KV, Rajan PS, Maheshkumar GS, Rajapandian S. Laparoscopic transabdominal preperitoneal repair of spigelian hernia. JSLS 2006; 10: 193-8.

22. Baucom C, Nguyen QD, Hidalgo M, Slakey D. Minimally invasive spigelian hernia repair. JSLS 2009; 13: 263-8.

23. Perrakis E, Velimazis G, Vezakis A, Antoniadis J, Patrikakos $V$. A new tension free technique for the repair of the umbilical hernia using the Prolene hernia System. Early results from 48 cases. Hernia 2003; 7: 178-80. 